\title{
Assessment of circulating tumor cells and serum markers for progression-free survival prediction in metastatic breast cancer: a prospective observational study
}

François-Clément Bidard ${ }^{1,2}$, David Hajage ${ }^{3}$, Thomas Bachelot ${ }^{4}$, Suzette Delaloge ${ }^{5}$, Etienne Brain ${ }^{6}$, Mario Campone ${ }^{7}$, Paul Cottu', Philippe Beuzeboc ${ }^{1}$, Emilie Rolland ${ }^{3}$, Claire Mathiot ${ }^{8}$ and Jean-Yves Pierga ${ }^{1,2^{*}}$

\begin{abstract}
Introduction: Circulating tumor cells (CTC) have been recently proposed as a new dynamic blood marker whose positivity at baseline is a prognostic factor and whose changes under treatment are correlated with progressionfree survival (PFS) in metastatic breast cancer patients. However, serum marker levels are also used for the same purpose, and no clear comparison has been reported to date.

Methods: The IC 2006-04 enrolled prospectively 267 metastatic breast cancer patients treated by first line chemotherapy and confirmed that CTC levels are an independent prognostic factor for PFS and overall survival (OS). A secondary pre-planned endpoint was to compare prospectively the positivity rates and the value of CTC (CellSearch ${ }^{\circledR}$ ), of serum tumor markers (carcinoembryonic antigen (CEA), cancer antigen 15.3 (CA 15-3), CYFRA 21-1), and of serum non-tumor markers (lactate deshydrogenase (LDH), alkaline phosphatase (ALP)) at baseline and under treatment for PFS prediction, independently from the other known prognostic factors, using univariate analyses and concordance indexes.

Results: A total of $90 \%$ of the patients had at least one elevated blood marker. Blood markers were correlated with poor performance status, high number of metastatic sites and with each other. In particular, CYFRA 21-1, a marker usually used in lung cancer, was elevated in $65 \%$ of patients. A total of $86 \%$ of patients had either CA $15-3$ and/or CYFRA 21-1 elevated at baseline. Each serum marker was associated, when elevated at baseline, with a significantly shorter PFS. Serum marker changes during treatment, assessed either between baseline and week 3 or between baseline and weeks 6 to 9, were significantly associated with PFS, as reported for CTC. Concordance indexes comparison showed no clear superiority of any of the serum marker or CTC for PFS prediction.
\end{abstract}

Conclusions: For the purpose of PFS prediction by measuring blood marker changes during treatment, currently available blood-derived markers (CTC and serum markers) had globally similar performances. Besides CEA and CA 15-3, CYFRA 21-1 is commonly elevated in metastatic breast cancer and has a strong prognostic value.

\section{Introduction}

Several serum markers have been developed in different types of cancer as tools for non-invasive assessment of the tumor burden, mostly in metastatic patients. Quantitative variations of serum markers are, therefore, often used in several cancer types as noninvasive tools to

\footnotetext{
* Correspondence: jean-yves.pierga@curie.net

'Department of Medical Oncology, Institut Curie, 26 rue d'Ulm, 75005 Paris, France

Full list of author information is available at the end of the article
}

assess treatment efficiency in metastatic patients. However, the use of serum tumor markers faces several issues and unanswered questions: their specificity and sensitivity are considered as low and no clear consensus exists on what threshold and/or variation should be considered clinically significant and which serum marker to follow.

In breast cancer, the commonly used serum markers are carcinoembryonic antigen (CEA), cancer antigen 27.29 (CA 27.29), and cancer antigen 15.3 (CA 15-3)
C Biomed Central 
[1]. CEA is a cell surface glycoprotein involved in cell adhesion, normally not present in the blood of healthy adults. CA 27.29, mostly used in North America, and CA 15-3, mostly used in Europe, correspond to two different epitopes of the same protein, MUC1, which is also a cell surface glycoprotein involved in cell adhesion. CYFRA 21-1, which is a commonly used serum marker in lung cancer [2], consists of cytokeratin-19 fragments which are specifically recognized by two monoclonal antibodies originally derived after injecting breast cancer cells (MCF7 cell line) into mice [3]. Small published reports, together with an empiric background at the Institut Curie, suggested that CYFRA 21-1 is commonly elevated and may be used for the management of metastatic breast cancers [4,5]. The 2007 American Society of Clinical Oncology update on tumor markers in breast cancer [6] reported that for monitoring patients with metastatic disease during therapy, CA 27.29 or CA $15-3$ can be used in conjunction with other monitoring tools, such as tumor response radiological assessment.

In 2004, circulating tumor cells (CTC) detection in blood by the CellSearch ${ }^{\circledR}$ system (Veridex, Raritan NJ, USA) was reported to be a prognostic marker in a study by Cristofanilli et al. [7]; moreover, changes in CTC count after one cycle of chemotherapy were associated with progression-free survival (PFS) [8]. On the basis of this first study, the FDA cleared the use of the CellSearch ${ }^{\circledR}$ system as a tool for monitoring chemotherapy in metastatic breast cancer patients, although no comparison with serum marker was initially reported. The prospective multicentric IC 2006-04 study was initiated in 2006 as a confirmatory study of the Cristofanilli's study, with the correlation of CTC changes and survival as the primary objective. We have recently reported this confirmatory objective of the study, which was clearly reached: CTC changes are a strong prognostic factor for both PFS and overall survival (OS) [9]. We report here, for the first time, the comparison of CTC with different serum tumor markers (CEA, CA 15-3, CYFRA 21-1) and non-tumor markers (lactate deshydrogenase LDH, alkaline phosphatase ALP), which was a prospectively planned secondary objective of the IC 2006-04 study.

\section{Materials and methods}

This prospective study was approved by the national ethics board, identified as DGS 2006-A00523-48 (France) and NCT00898014 (USA) and was conducted in five different French comprehensive cancer centers.

\section{Patients and treatment}

The main eligibility requirements for this study included the patient's written informed consent, metastatic breast cancer, patients entering first-line chemotherapy (chosen by clinicians) with or without targeted therapy, life expectancy of at least three months, and measurable or evaluable disease. Clinical evaluations were conducted as usual, but were mandatory at inclusion (before cycle 1 , that is, week 0 ) and at the first radiological evaluation before cycle 3 or 4 (C3/4, that is, weeks 6 to 9). Radiological evaluations (RECIST [10]) were mandatory at inclusion and before $\mathrm{C} 3 / 4$. The following blood tests were obtained at inclusion, before cycle 2 (C2), C3/4, and at progression: complete blood count, liver function (including LDH and ALP), serum calcium and serum markers: CEA, CA 15-3 and CYFRA 21-1. These blood tests were processed locally and disclosed to clinicians. CTC were analyzed at four different time-points in an experienced laboratory (Institut Curie, Paris): at inclusion (before starting treatment), before $\mathrm{C} 2$, before $\mathrm{C} 3 / 4$ and at disease progression (not shown). CTC counts were not disclosed to clinicians. Technical details of the CellSearch $^{\circledR}$ technique have been described elsewhere [11].

\section{Objectives and statistics}

The study was powered for its main objective that consisted of detecting among patients with $\geq 5$ CTC/7.5 ml at baseline, a $35 \%$ difference in six-month PFS rates between patients with a CTC count $<$ or $\geq 5$ CTC/7.5 $\mathrm{ml}$ before $\mathrm{C} 2$. The study was not specially powered for its planned secondary objectives, including this comparison with serum tumor markers. Data are expressed as means or numbers (\%). Categorical variables were compared by chi-square or Fisher's exact test, and continuous variables were compared by Student's $t$-test or Wilcoxon's rank-sum test. Kaplan-Meier progression free survival (PFS) curves were computed according to CTC counts $(<$ or $\geq 5 \mathrm{CTC} / 7.5 \mathrm{ml})$ and other tumor markers (< or $\geq$ Upper Limit of Normal Value (ULNV)), and were compared using log-rank tests. Progression was defined as local or distant relapse or death by any cause. Concordance index was also computed for each marker as continuous variables, PFS as outcome. Univariate analysis was performed using hazard ratios and 95\% CI for PFS for each clinical characteristic and for each tumor marker or CTCs separately. A concordance index for PFS based on a clinical model (a model including all the above clinical characteristics) was used to show by how much each tumor marker or CTCs improved the performance of the clinical model in a multivariate analysis. Significance was defined as $P \leq$ 0.05. Statistical analyses were performed using R2.12.1 software (Wien University, Wien, Austria)[12]

\section{Results}

From June 2007 to September 2009, 267 patients with a median age of 57 years were included in the IC 2006-04 study. With a median follow-up of 14.9 months, 161 
tumor progressions $(60 \%)$ were recorded at the time of analysis.

\section{Detection rates at baseline}

CTC and serum marker values at inclusion repartition in percentile, mean, median range are given in Table 1 and Figure 1. Values for serum markers are expressed in ULNV: upper limit of normal value. Table 2 shows elevated serum marker (> ULNV) and CTC $(\geq 5 \mathrm{CTC} / \mathrm{ml})$ incidence rates at baseline: CA 15-3 and CYFRA 21-1 were the two most commonly elevated serum markers. Serum markers and CTC were highly correlated to performance status, number of metastatic sites and to each other. Table 3 shows the percentage of patients who had at least one marker elevated at baseline according to different marker combinations. As expected, this percentage globally increases with the number of markers assessed. However, the combination of CA 15-3 and CYFRA 21-1 retrieved almost the same positivity rate (86\%) than all four markers (90\%).

\section{Single assessment and association with PFS}

When elevated, all markers tested at baseline had a negative prognostic impact in univariate analysis, as shown in Figure 2. The concordance index (and 95\% confidence interval), which quantifies the quality of ranking and is a common performance measure for assessing learned models in survival analysis, was calculated for each marker, with PFS as the outcome. Concordance indexes with PFS were, at baseline, $\mathrm{C}$-index ALP $_{\mathrm{ALP}}$ $=0.56(0.50$ to 0.61$)(n=238), \mathrm{C}$-index $\mathrm{CA}_{\mathrm{CA} 15-3}=0.56$ (0.51 to 0.61$)(n=244), \mathrm{C}$-index ${ }_{\mathrm{CEA}}=0.58(0.52$ to $0.64)(n=210), \mathrm{C}$-index ${ }_{\text {CTC }}=0.61(0.56$ to 0.66$)(n=$ 257), C-index CYFRA21-1 $=0.67$ (0.62 to 0.72$)(n=190)$ and $\mathrm{C}$-index $\mathrm{x}_{\mathrm{LDH}}=0.68(0.63$ to 0.73$)(n=218)$. These results showed that the markers' performances were globally close to each other, with ALP having the worst result and CYFRA 21-1 and LDH the best. Similar results were obtained when markers were assessed during treatment, before cycle 2 (three to four weeks later, Figure 3 ) and before cycles 3 to 4 (six to nine weeks later, not shown).
In a univariate analysis for PFS, performance status, number of metastatic sites and triple-negative status were statistically significant for PFS (Table 4). At multivariate analysis, only performance status and triple negative tumor status were independent clinical prognostic factors and were included in a clinical model. CTC, LDH, CYFRA21.1, CEA and CA15.3 were statistically significant for PFS and not ALP. When the concordance index was calculated for each tumor marker or CTCs added to the clinical model, all of them, except ALP, slightly improved the performance of the clinical model. The C-index of the clinical model (0.697) increased from 0.71 to 0.723 , except with ALP.

\section{Changes under treatment and association with PFS}

By combining marker status (elevated or not) before cycle 1 and before cycle 2, four subgroups could be separated for each marker. Figure 4 shows that these early changes were highly correlated with PFS in univariate analysis for all the markers; globally, patients with non-elevated markers at both time points had longer PFS; patients with elevated markers at both time points had generally the worst PFS. However, even in these groups of worst prognosis, median PFS was longer than six months for every marker tested, suggesting that none of these marker's early changes can predict accurately very short PFS. Concordance indexes with PFS were $C$-index ${ }_{\text {СтC }}=0.57(0.51$ to 0.63$)(n=201), C$ index $_{\mathrm{ALP}}=0.50(0.44$ to 0.56$)(n=195), \mathrm{C}$-index $\mathrm{CEEA}_{\mathrm{C}}=$ $0.45(0.38$ to 0.51$)(n=157), C$-index ${ }_{\text {CA15-3 }}=0.50(0.44$ to 0.56$)(n=193), \mathrm{C}$-index ${ }_{\text {CYFRA21-1 }}=0.57$ (0.50 to $0.65)(n=142)$ and C-index $\mathrm{LDH}_{\mathrm{LD}}=0.63(0.55$ to 0.70$)(n$ =136). Again, these results showed that marker performances were extremely close to each other.

As a spurious early rise of serum markers may occur during the first weeks of a new chemotherapy and may lower the above serum markers' concordance indexes, we also studied the changes that occur before cycle 1 and before cycles 3 to 4; Figure 5 shows that these changes were also significant for all the markers. We calculated the concordance indexes by combining marker status before cycle 1 and before cycle 3/4 (weeks 6

Table 1 CTC and serum marker values repartition at inclusion

\begin{tabular}{|c|c|c|c|c|c|c|c|c|}
\hline & Mean & SD & Quantile 0\% & Quantile 25\% & Quantile $50 \%$ (median) & Quantile 75\% & Quantile $100 \%$ & $\mathbf{N}$ \\
\hline CTC & 81.65 & 324.76 & 0 & 0 & 2.5 & 23.25 & 3,369 & 260 \\
\hline CA15.3 & 7.53 & 23.77 & 0.14 & 0.7 & 1.76 & 4.45 & 314.1 & 247 \\
\hline CEA & 7.20 & 18.23 & 0.04 & 0.4 & 1 & 3.45 & 146.13 & 212 \\
\hline CYFRA21 & 9.01 & 29.51 & 0.1 & 0.65 & 1.95 & 5.25 & 284.54 & 191 \\
\hline $\mathrm{LDH}$ & 1.39 & 2.02 & 0.28 & 0.71 & 0.92 & 1.45 & 25.54 & 220 \\
\hline ALP & 1.056 & 1.00 & 0.26 & 0.58 & 0.79 & 1.06 & 10 & 241 \\
\hline
\end{tabular}

CTC and serum markers values at inclusion repartition in percentile, mean, median range. Values for serum marker are expressed in ULNV, upper limit of the normal value 


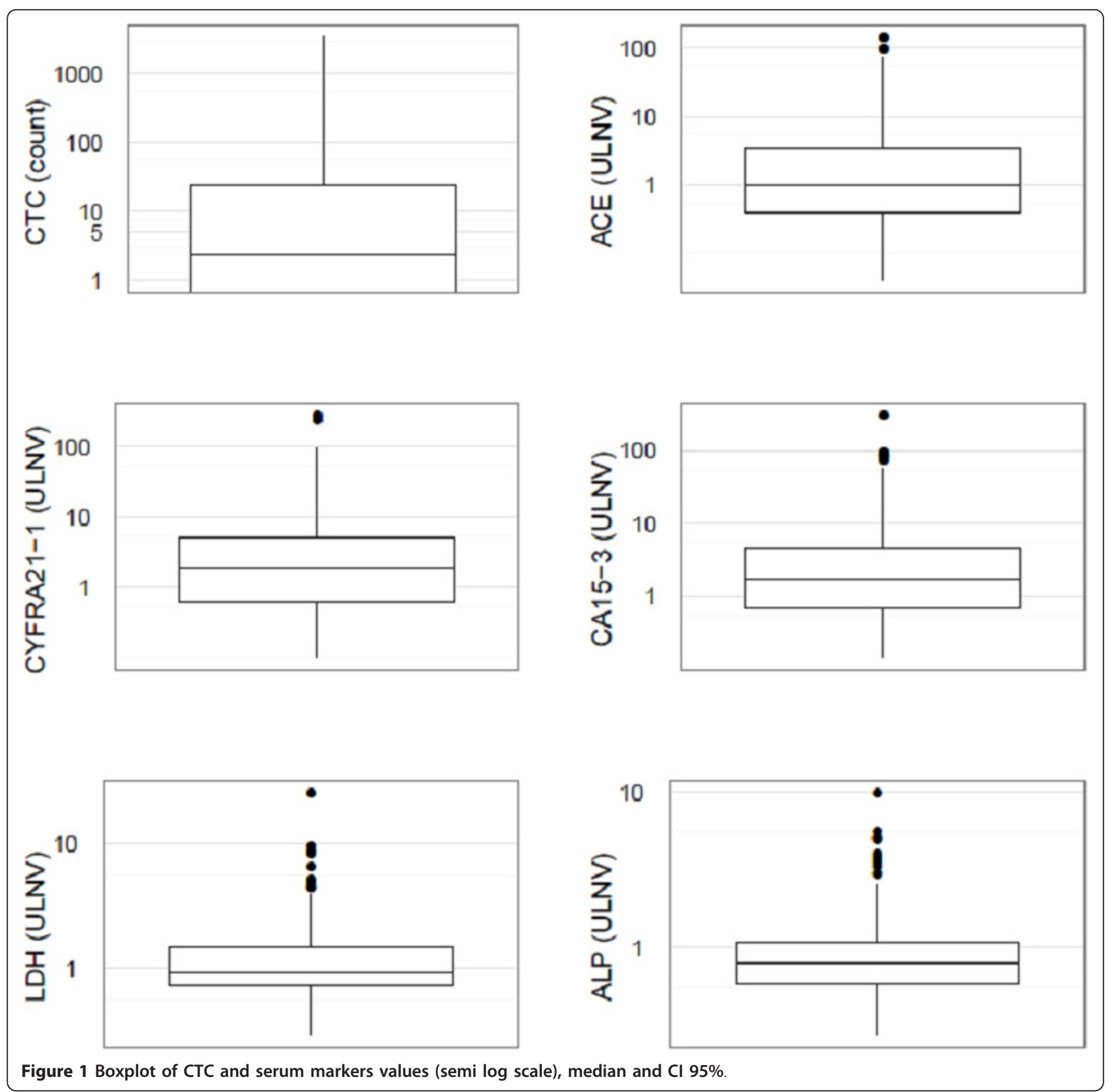

to 9). The concordance indexes for the five serum markers and for CTC were all between 0.61 and 0.66 , with largely overlapping $95 \%$ confidence intervals.

\section{CTC prognostic value according to serum marker subgroups}

Finally, interaction tests have been performed to further study if the prognostic value of baseline CTC count and of CTC count changes under treatment were restricted and/or different according to the different patient's subgroup, including serum marker subgroups (for example, in patients with non-elevated CEA vs elevated CEA). These tests were non significant.

\section{Discussion}

The need for novel independent prognostic factors in metastatic breast cancer patients is much lower than the need for dynamic blood markers, which can indicate the treatment efficiency in a reliable and early fashion. Serum tumor markers are an easy, quick, cheap, but rather imprecise and sometimes misleading tool, to monitor the treatment efficacy. However, they are 
Table 2 Detection rates of elevated markers at baseline

\begin{tabular}{|c|c|c|c|c|c|c|c|}
\hline Patient characteristics & $\begin{array}{l}\mathrm{N} \text { patients } \\
\text { assessed }\end{array}$ & $\begin{array}{l}\text { CA } 15-3> \\
\text { ULNV }\end{array}$ & $\begin{array}{l}\text { CEA > } \\
\text { ULNV }\end{array}$ & $\begin{array}{c}\text { CYFRA } 21-1> \\
\text { ULNV }\end{array}$ & $\begin{array}{l}\text { LDH > } \\
\text { ULNV }\end{array}$ & $\begin{array}{l}\text { ALP > } \\
\text { ULNV }\end{array}$ & $\overline{\mathrm{CTC}} \geq 5$ \\
\hline Menopausal status & & NS & NS & $P=0.01$ & NS & NS & NS \\
\hline Premenopausal & 113 & $42 \%$ & $44 \%$ & $54 \%$ & $44 \%$ & $25 \%$ & $45 \%$ \\
\hline Postmenopausal & 148 & $58 \%$ & $56 \%$ & $72 \%$ & $45 \%$ & $33 \%$ & $43 \%$ \\
\hline Receptor status & & NS & $P=0.002$ & NS & NS & NS & NS \\
\hline Horm. positive & 159 & $68 \%$ & $58 \%$ & $65 \%$ & $40 \%$ & $33 \%$ & $46 \%$ \\
\hline HER2 positive & 45 & $60 \%$ & $51 \%$ & $56 \%$ & $49 \%$ & $32 \%$ & $34 \%$ \\
\hline Triple negative & 54 & $57 \%$ & $27 \%$ & $74 \%$ & $53 \%$ & $19 \%$ & $46 \%$ \\
\hline Tumor grade & & NS & $P=0.05$ & NS & NS & $P=0.03$ & NS \\
\hline 1 & 26 & $77 \%$ & $76 \%$ & $64 \%$ & $37 \%$ & $52 \%$ & $48 \%$ \\
\hline 2 & 106 & $64 \%$ & $55 \%$ & $62 \%$ & $43 \%$ & $28 \%$ & $41 \%$ \\
\hline 3 & 123 & $63 \%$ & $45 \%$ & $68 \%$ & $47 \%$ & $25 \%$ & $45 \%$ \\
\hline Performance status & & $P=0.003$ & $P=0.02$ & $P<10^{-4}$ & $P<10^{-4}$ & $P=0.001$ & $P<10^{-4}$ \\
\hline 0 & 123 & $55 \%$ & $42 \%$ & $51 \%$ & $21 \%$ & $18 \%$ & $29 \%$ \\
\hline 1 & 97 & $69 \%$ & $57 \%$ & $70 \%$ & $58 \%$ & $34 \%$ & $49 \%$ \\
\hline 2 & 22 & $82 \%$ & $53 \%$ & $79 \%$ & $79 \%$ & $52 \%$ & $71 \%$ \\
\hline 3 or 4 & 13 & $92 \%$ & $78 \%$ & $100 \%$ & $100 \%$ & $54 \%$ & $92 \%$ \\
\hline $\begin{array}{c}\text { Number of metastatic } \\
\text { sites }\end{array}$ & & $P=0.02$ & NS & $P=0.001$ & $P<10^{-4}$ & NS & $\begin{array}{l}P= \\
0.03\end{array}$ \\
\hline$<3$ & 155 & $60 \%$ & $52 \%$ & $55 \%$ & $37 \%$ & $28 \%$ & $39 \%$ \\
\hline$\geq 3$ & 106 & $71 \%$ & $51 \%$ & $80 \%$ & $56 \%$ & $31 \%$ & $48 \%$ \\
\hline CA 15.3 & & - & $P<10^{-4}$ & $P<10^{-4}$ & $P<10^{-4}$ & $P<10^{-4}$ & $P<10^{-4}$ \\
\hline$\leq$ ULNV & 88 & - & $24 \%$ & $54 \%$ & $25 \%$ & $13 \%$ & $26 \%$ \\
\hline > ULNV & 159 & - & $68 \%$ & $72 \%$ & $56 \%$ & $40 \%$ & $53 \%$ \\
\hline CEA & & - & - & $P=0.005$ & $P=0.009$ & $P=0.001$ & $\begin{array}{l}P= \\
0.03\end{array}$ \\
\hline$\leq$ ULNV & 103 & - & - & $56 \%$ & $36 \%$ & $18 \%$ & $35 \%$ \\
\hline > ULNV & 109 & - & - & $75 \%$ & $55 \%$ & $38 \%$ & $49 \%$ \\
\hline CYFRA 21-1 & & - & - & - & $P<10^{-4}$ & NS & $P<10^{-4}$ \\
\hline$\leq$ ULNV & 66 & - & - & - & $16 \%$ & $23 \%$ & $19 \%$ \\
\hline$>$ ULNV & 125 & - & - & - & $63 \%$ & $34 \%$ & $56 \%$ \\
\hline LDH & & - & - & - & - & $P=0.02$ & $P<10^{-4}$ \\
\hline$\leq$ ULNV & 121 & - & - & - & - & $22 \%$ & $25 \%$ \\
\hline$>$ ULNV & 99 & - & - & - & - & $36 \%$ & $67 \%$ \\
\hline ALP & & - & - & - & & - & $P<10^{-4}$ \\
\hline$\leq$ ULNV & 170 & - & - & - & - & - & $36 \%$ \\
\hline$>$ ULNV & 71 & - & - & - & - & - & $65 \%$ \\
\hline $\begin{array}{l}\text { All population } \\
\text { at baseline }\end{array}$ & & $64 \%$ & $51 \%$ & $65 \%$ & $45 \%$ & $29 \%$ & $44 \%$ \\
\hline $\begin{array}{l}\text { All population } \\
\text { before cycle } 2\end{array}$ & & $66 \%$ & $46 \%$ & $34 \%$ & $43 \%$ & $28 \%$ & $17 \%$ \\
\hline $\begin{array}{l}\text { All population } \\
\text { before cycle } 3 / 4\end{array}$ & & $64 \%$ & $40 \%$ & $27 \%$ & $49 \%$ & $22 \%$ & $13 \%$ \\
\hline
\end{tabular}

ULNV: upper limit of normal value. P-values were obtained by Pearson's Chi-square test. Horm. positive: either estrogen and/or progesterone receptor positive by immunohistochemistry on primary tumor. HER2 positive: HER2 overexpressed by immunohistochemistry or amplified by FISH in $2+$ cases. Triple negative: estrogen, progesterone and HER2 negative primary tumor. NS, non significant. Significant associations $(P \leq 0.05)$ are in bold.

particularly valuable for treatment monitoring in patients that have disease that cannot be evaluated by radiology. CTC count by the CellSearch ${ }^{\circledR}$ system is a validated prognostic factor at baseline, but is also used for treatment monitoring [13-15]. This test is, however, more expensive than serum tumor markers and has never been directly compared with them. The IC 200604 is the first large prospective study in which a comparison between CTC and five different serum markers was pre-planned.

At first, our study tried to answer a recurrent issue for medical oncologists, that is "which serum marker should 
Table 3 Percentage of patients with at least one elevated marker at baseline

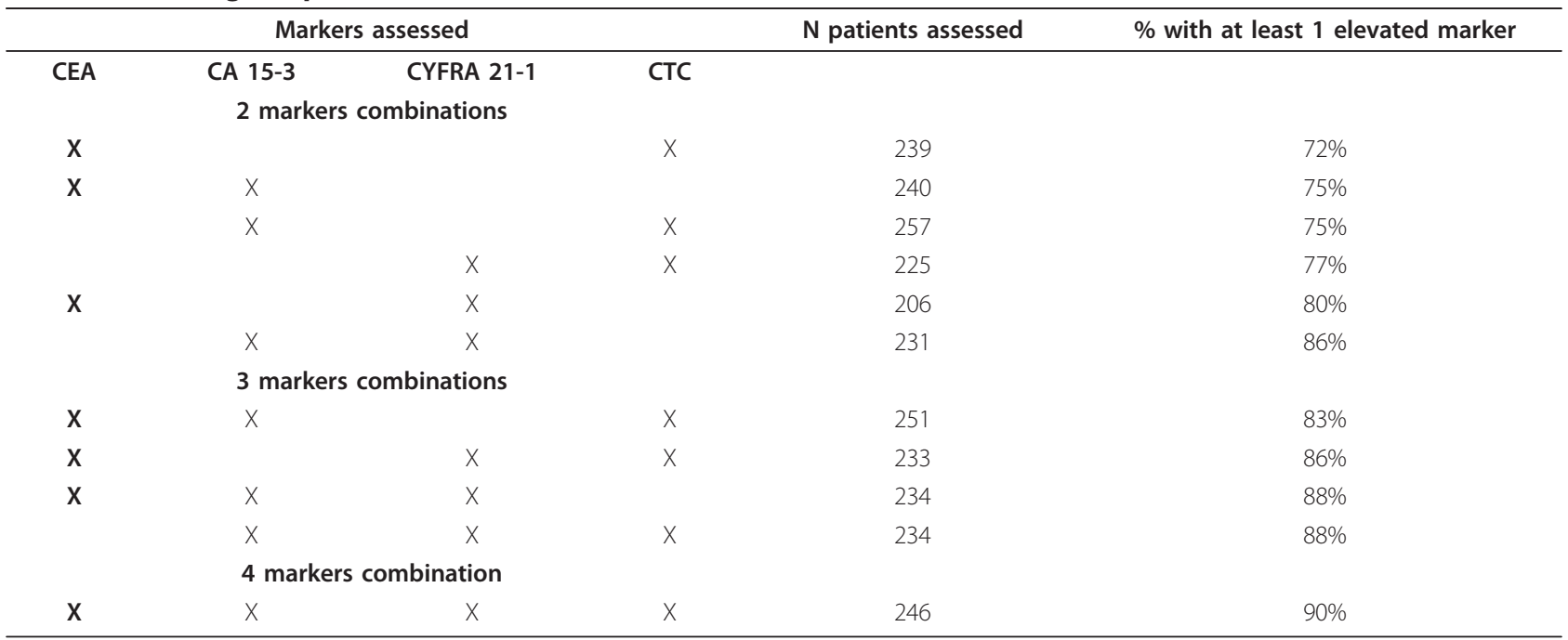

Single marker positivity rates are given for each of the markers, Table 2 .

I ask for?" To be considered as informative and usable for further determination under therapy, a serum marker should be elevated at baseline, before the start of therapy. Historically, comparison between serum markers mostly used positivity rates (> ULNV) at baseline in metastatic patients [16]. For serum markers and CTC, incidence rates were in line with those previously reported at first metastatic relapse $[17,18]$, together with the low incidence of CEA in triple-negative cancers [19]. Our study shows that repeated CTC counts are

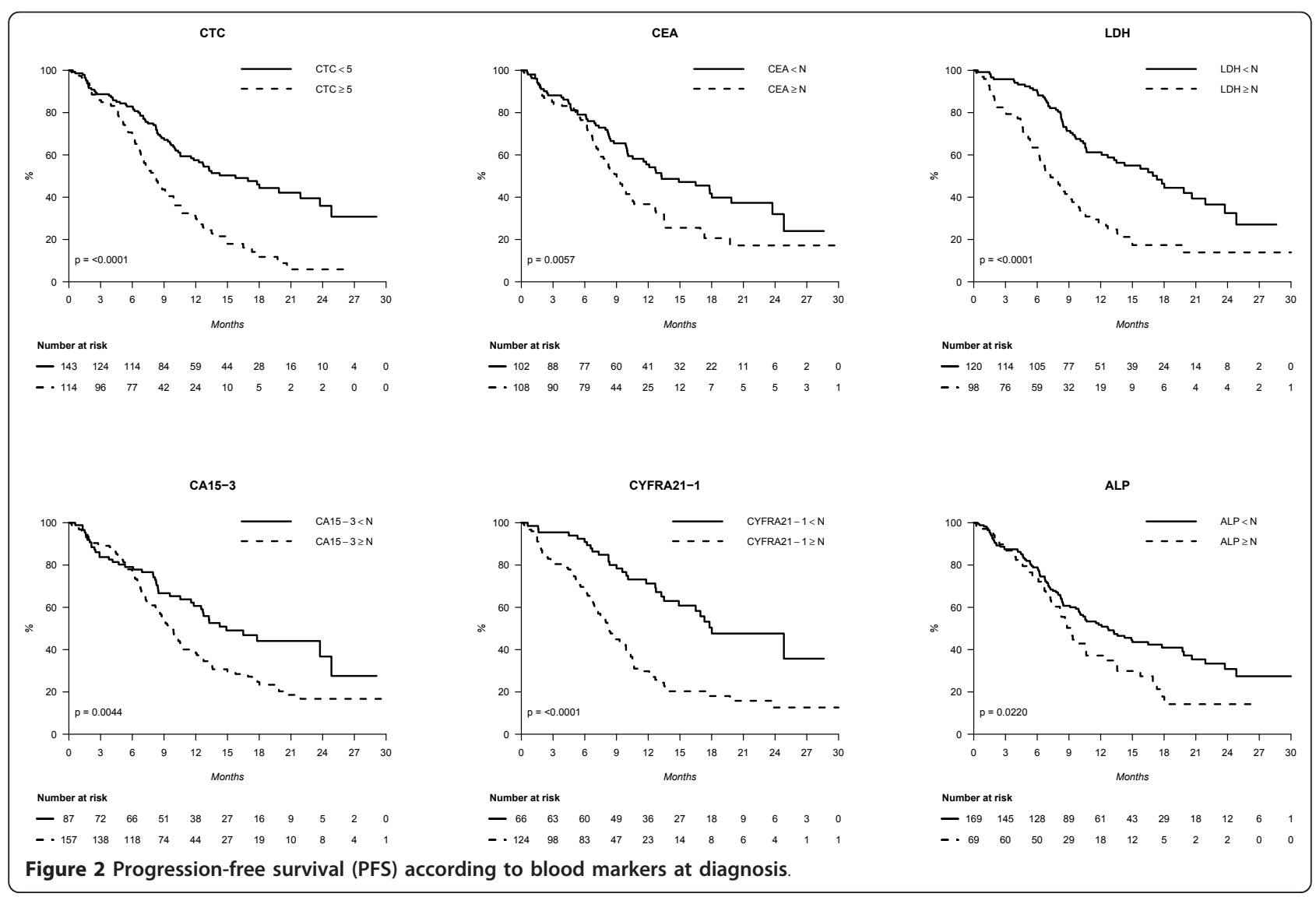




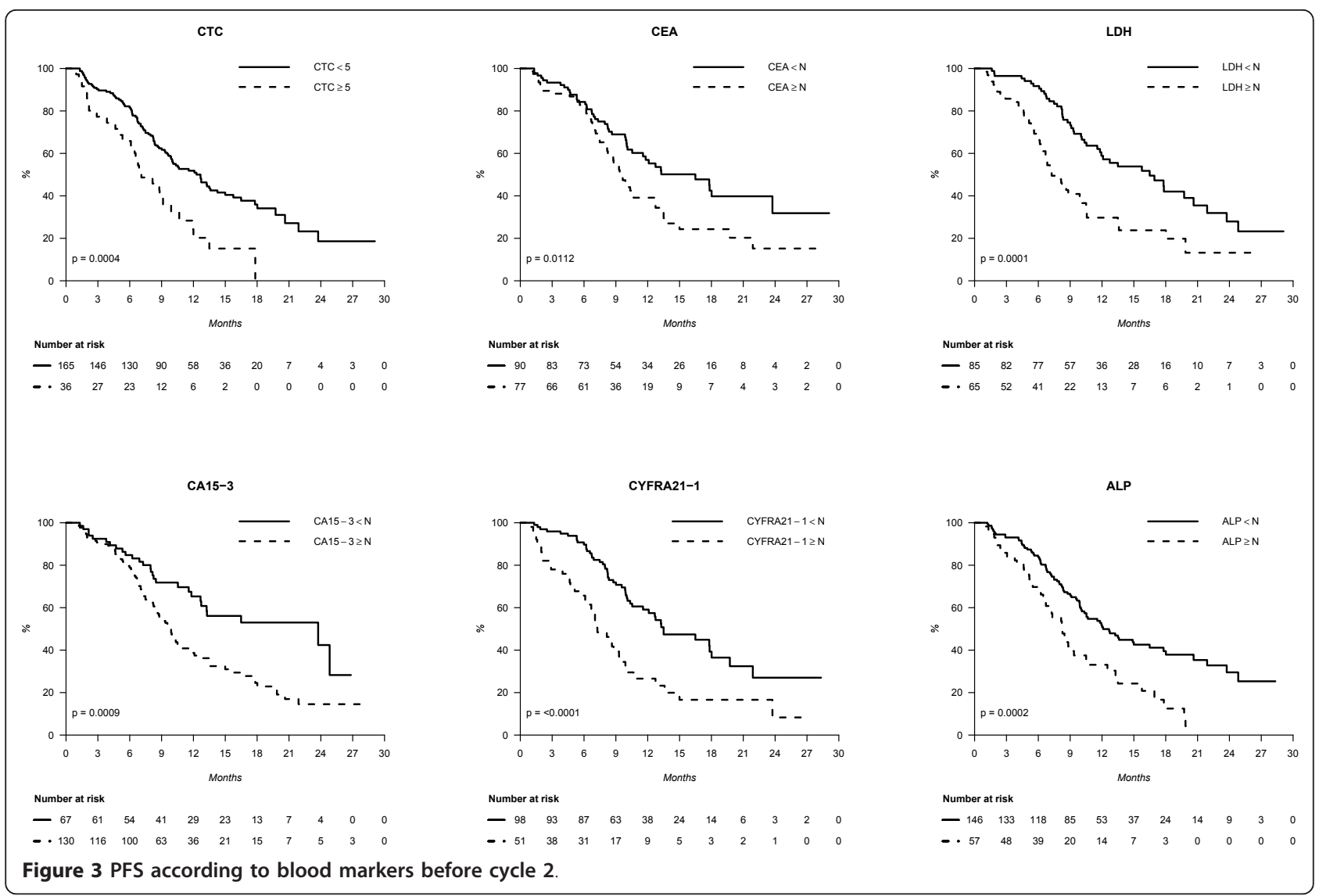

informative mainly for patients who have an elevated level at baseline $(\geq 5 \mathrm{CTC} / 7.5 \mathrm{ml})$, but not for patients initially CTC negative $(<5 \mathrm{CTC} / 7.5 \mathrm{ml})$, as only two of these patients will present an increase $(\geq 5 \mathrm{CTC} / 7.5 \mathrm{ml})$ during treatment (Figure 3). Due to the very small number of these patients, no conclusion can be drawn on the prognostics of this subgroup. On the basis of baseline positivity rate comparison, assessing only CEA and CA 15-3, the two most commonly used breast cancer serum markers retrieve around $75 \%$ of patients with at least one marker elevated at baseline. Our study has also investigated CYFRA 21-1 as a breast cancer serum marker, which turned out to be the most commonly elevated serum tumor marker ( $65 \%$ of patients), as already suggested in smaller studies [20,21]. Adding either CYFRA 21-1 or CTC to this CEA and CA 15-3 combination further increases this percentage to around $90 \%$ of patients, but assessing the full four-marker panel (CEA, CA 15-3, CYFRA 21-1 and CTC) did not further improve the overall positivity rate. Among the different markers tested, a drop in positivity rates between baseline and cycle 3/4 was mostly observed for CTC and CYFRA $21-1$ : 44 to $13 \%$ and 65 to $27 \%$ respectively (Table 2).
We showed that serum markers and CTC positivity were highly correlated with other known clinical prognostic factors, such as poor performance status or the high number of metastatic sites. Interestingly, neither serum markers nor CTC detection were correlated with immunohistological subtypes (hormone receptors-positive, HER2-positive or triple-negative breast cancers). Unsurprisingly, each of the markers tested had a significant impact on PFS in univariate analysis. Multivariate analyses, including serum markers, CTC and known clinical prognostic factors, have been reported previously: CTC and CEA were the two blood markers independently associated with PFS, whereas CTC count was the only blood marker independently associated with OS [9].

Here, by comparing the early and late changes of five blood markers together with CTC changes for PFS prediction, we showed no clear superiority of CTC over the other serum markers. This result was, however, not the primary endpoint of our study, and the statistical power of these analyses may still be discussed, although performed in more than 200 patients. For this analysis, we used the "prognosis-optimized" threshold of $\geq 5 \mathrm{CTC} / 7.5 \mathrm{ml}$, which was initially 
Table 4 Contribution of each serum marker and CTCs to a clinical model

\begin{tabular}{|c|c|c|c|c|c|c|c|c|}
\hline Variable & Univariate & $\begin{array}{l}\text { Multiv } \\
\text { clin }\end{array}$ & $\begin{array}{l}\text { Multiv clin + } \\
\text { CTC }\end{array}$ & $\begin{array}{l}\text { Multiv clin + CA } \\
15.3\end{array}$ & $\begin{array}{l}\text { Multiv clin + } \\
\text { CYFRA } 21\end{array}$ & $\begin{array}{l}\text { Multiv clin + } \\
\text { CEA }\end{array}$ & $\begin{array}{l}\text { Multiv clin + } \\
\text { LDH }\end{array}$ & $\begin{array}{l}\text { Multiv clin + } \\
\text { ALP }\end{array}$ \\
\hline Triple neg. & $\begin{array}{l}3.05 \\
(2.14 ; 4.36)\end{array}$ & $\begin{array}{l}3.55 \\
(2.43 ; \\
5.18)\end{array}$ & $\begin{array}{l}3.33 \\
(2.06 ; 5.39)\end{array}$ & $\begin{array}{l}3.27 \\
(2.03 ; 5.30)\end{array}$ & $\begin{array}{l}3.14 \\
(1.95 ; 5.06)\end{array}$ & $\begin{array}{l}4.417 \\
(2.628 ; 7.425)\end{array}$ & $\begin{array}{l}3.061 \\
(1.89 ; 4.95)\end{array}$ & $\begin{array}{l}3.344 \\
(2.062 ; 5.423)\end{array}$ \\
\hline PS $>0$ & $\begin{array}{l}2.30 \\
(1.65 ; 3.21)\end{array}$ & $\begin{array}{l}2.659 \\
(1.89 ; \\
3.741)\end{array}$ & $\begin{array}{l}2.097 \\
(1.319 ; 3.33)\end{array}$ & $\begin{array}{l}2.359 \\
(1.509 ; 3.69)\end{array}$ & $\begin{array}{l}2.133 \\
(1.35 ; 3.36)\end{array}$ & $\begin{array}{l}2.428 \\
(1.56 ; 3.78)\end{array}$ & $\begin{array}{l}1.968 \\
(1.21 ; 3.19)\end{array}$ & $\begin{array}{l}2.49 \\
(1.58 ; 3.93)\end{array}$ \\
\hline $\begin{array}{l}\mathrm{Nb} \text { of metastatic } \\
\text { sites }>2\end{array}$ & $\begin{array}{l}1.886 \\
(1.378 ; \\
2.581)\end{array}$ & NS & & & & & & \\
\hline $\mathrm{CTC} \geq 5$ & $\begin{array}{l}2.263 \\
(1.644 ; \\
3.115)\end{array}$ & & $\begin{array}{l}1.996 \\
(1.277 ; 3.122)\end{array}$ & & & & & \\
\hline CA15-3 $\geq$ ULNV & $\begin{array}{l}1.665 \\
(1.167 ; \\
2.374)\end{array}$ & & & $\begin{array}{l}1.746 \\
(1.095 ; 2.783)\end{array}$ & & & & \\
\hline $\begin{array}{l}\text { CYFRA 21-1 } \geq \\
\text { ULNV }\end{array}$ & $\begin{array}{l}2.901 \\
(1.896 ; \\
4.439)\end{array}$ & & & & $\begin{array}{l}2.097 \\
(1.27 ; 3.46)\end{array}$ & & & \\
\hline CEA $\geq$ ULNV & $\begin{array}{l}1.64 \\
(1.151 ; \\
2.337)\end{array}$ & & & & & $\begin{array}{l}2.015 \\
(1.272 ; 3.191)\end{array}$ & & \\
\hline LDH $\geq$ ULNV & $\begin{array}{l}2.525 \\
(1.781 ; \\
3.579)\end{array}$ & & & & & & $\begin{array}{l}1.933 \\
(1.203 ; 3.104)\end{array}$ & \\
\hline$A L P \geq U L N V$ & $\begin{array}{l}1.501 \\
(1.058 ; \\
2.131)\end{array}$ & & & & & & & $\begin{array}{l}1.108 \\
(0.684 ; 1.793)\end{array}$ \\
\hline C-INDEX & & $\begin{array}{l}0.697 \\
(0.65 ; \\
0.75)\end{array}$ & $\begin{array}{l}0.71 \\
(0.663 ; 0.767)\end{array}$ & $\begin{array}{l}0.713 \\
(0.661 ; 0.765)\end{array}$ & $\begin{array}{l}0.723 \\
(0.68 ; 0.77)\end{array}$ & $\begin{array}{l}0.714 \\
(0.664 ; 0.765)\end{array}$ & $\begin{array}{l}0.717 \\
(0.668 ; 0.766)\end{array}$ & $\begin{array}{l}0.688 \\
(0.637 ; 0.74)\end{array}$ \\
\hline
\end{tabular}

Univariate analysis using hazard ratios and $95 \% \mathrm{Cl}$ for PFS for each clinical characteristic in the first column. Multivariate analysis for clinical parameters (second column) (Multiv. clin) Contribution for each tumor marker or CTCS to clinical model (Multiv.clin + serum marker) Last line: Concordance indexes for PFS for clinical model including all the clinical characteristics and for each tumor marker or CTCs.

defined as the best dichotomizing threshold for PFS and OS prediction by CTC at baseline and under treatment [7]. Contrarily, for serum tumor markers, the upper limits of normal values (ULNV) were historically defined by healthy-donor analyses, and no cut-off has been optimized previously for survival prediction. In this study, it was pre-analytically planned to use ULNV as the positivity threshold at both baseline and before cycle 2 and, as for CTC counts, to divide the population into four subgroups according to the marker at baseline and before cycle 2 . Other models may have been used for serum markers, in order to take into account the relative changes of elevated marker (for example, $50 \%$ decrease between baseline at cycle $2 \ldots$ ), but testing all the possibilities for serum marker analyses would have led to multiple testing biases favoring serum markers over CTC.

\section{Conclusion}

Finally, the IC 2006-04 study suggests that CTC count should not be considered alone, but should be put into the current clinical context of metastatic breast cancer. We previously demonstrated that CTC, but not serum markers, has an independent prognostic value in multivariate analysis. This prognostic value did not interact with any tested subgroup. However, when focusing on the different blood markers assessable for PFS prediction before and during treatment, we report here that there is no clear superiority of CTC count over serum markers. Markers predicting or monitoring treatment efficiency are much more needed for patients with metastatic breast cancer than prognostic serum markers. A further prospective comparative study would be required to obtain a definite conclusion with a predefined statistical power. As, to our knowledge, no such study is ongoing, we believe that the IC 2006-04 will remain the largest prospective study with a CTC/serum marker comparison. The interest of implementing CTC count into the routine management of metastatic breast cancer chemotherapy will be finally assessed in the two ongoing randomized trials SWOG500 (USA) and CirCe01 (France). 

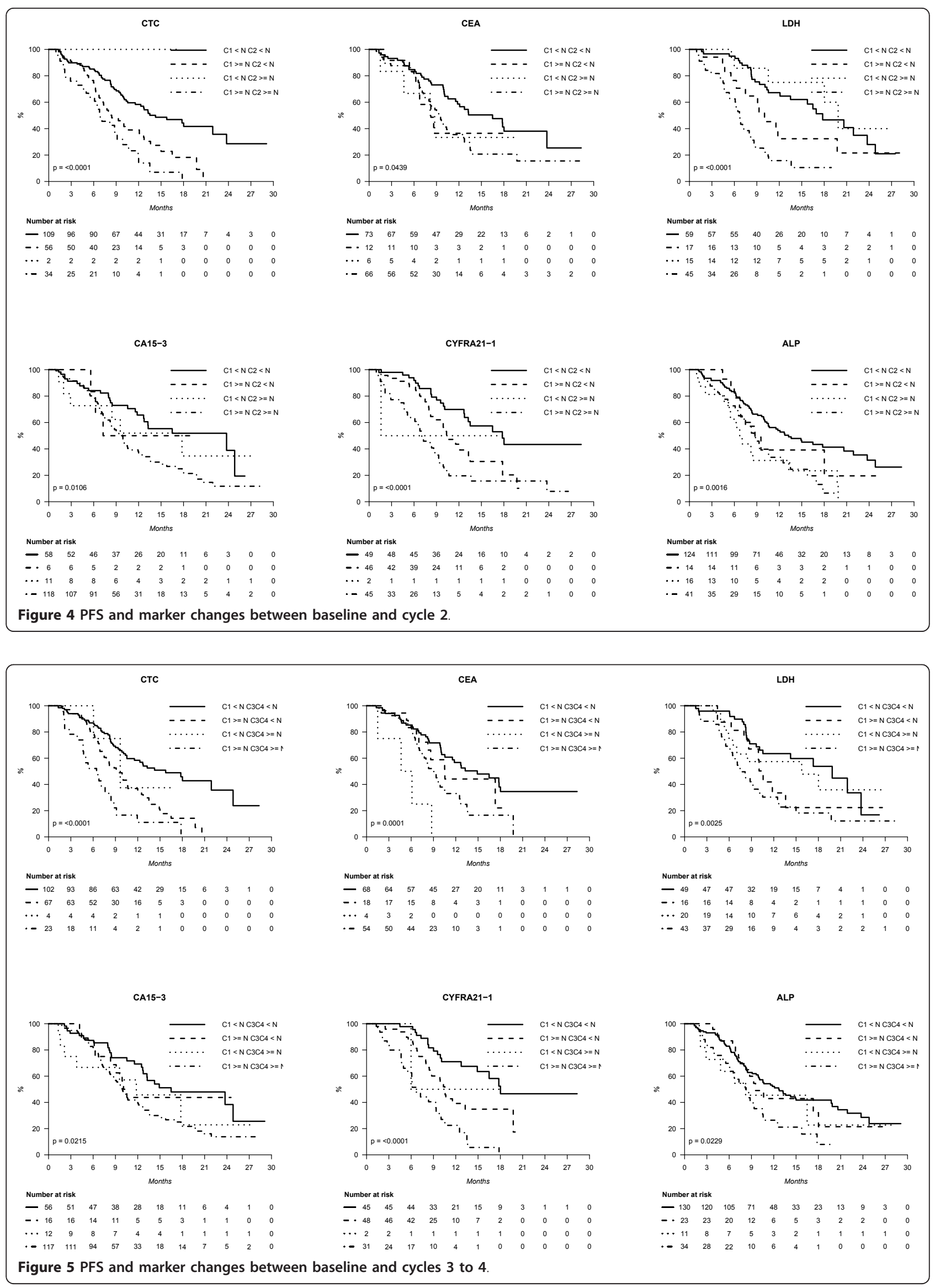


\section{Abbreviations}

ALP: alkaline phosphatase; C2: cycle 2 (of chemotherapy); C3/4: cycle 3/4 (of chemotherapy); CA: cancer antigen; CEA: carcinoembryonic antigen; CTC: circulating tumor cell; LDH: lactate deshydrogenase; OS: overall survival; PFS: progression-free survival; ULNV: upper limit of normal value.

\section{Acknowledgements}

This study was funded by a public grant from the French government (PHRC AOM06156). The authors are grateful to Mustapha Khazour and Isabelle Vaucher for technical assistance, Bernard Asselain for statistics, and Sébastien Armanet, Samia Thebti and Sylvie Maral for data collection (all at Institut Curie, Paris).

\section{Author details}

${ }^{1}$ Department of Medical Oncology, Institut Curie, 26 rue d'Ulm, 75005 Paris, France. ${ }^{2}$ Université Paris Descartes, 12 rue de l'école de Médecine, 75006 Paris, France. ${ }^{3}$ Department of Biostatistics, Institut Curie, 26 rue d'Ulm, 75005 Paris, France. ${ }^{4}$ Department of Medical Oncology, Centre Léon Bérard, 28 rue Laënnec, 69008 Lyon, France. ${ }^{5}$ Department of Medical Oncology, Institut Gustave Roussy, 114 rue Vaillant, 94800 Villejuif, France. ${ }^{6}$ Department of Medical Oncology, Institut Curie, Hôpital René Huguenin, 35 rue Dailly, 92210 Saint Cloud, France. ${ }^{7}$ Department of Medical Oncology, Institut de Cancérologie de l'Ouest, Bd Monod, 44800 Saint Herblain, France.

${ }^{8}$ Hematology laboratory, Institut Curie, 26 rue d’Ulm, 75005 Paris, France.

\section{Authors' contributions}

FCB participated to data collection, data interpretation and statistical analyses, and wrote the manuscript. $\mathrm{DH}$ supervised data management and performed statistical analyses. TB, SD, EB, MC, PC and PB participated in the design of the study and included patients in the study. ER coordinated data management and participated in statistical analyses. CM supervised the central laboratory for CTC detection. JYP conceived of the study, and participated in its design and coordination, and data interpretation and manuscript writing. All authors read and approved the final manuscript.

\section{Competing interests}

J-YP received research grants and lecture honoraria from Veridex. F-CB received lecture honoraria from Veridex. The other authors have no disclosures. This study was presented in part at the 2010 San Antonio Breast Cancer Symposium and at the 2011 IMPAKT conference (oral presentations).

Received: 1 August 2011 Revised: 13 November 2011

Accepted: 13 February 2012 Published: 13 February 2012

\section{References}

1. Bast RC Jr, Ravdin P, Hayes DF, Bates S, Fritsche H Jr, Jessup JM, Kemeny N, Locker GY, Mennel RG, Somerfield MR: 2000 update of recommendations for the use of tumor markers in breast and colorectal cancer: clinical practice guidelines of the American Society of Clinical Oncology. J Clin Oncol 2001, 19:1865-1878.

2. Ardizzoni A, Cafferata MA, Tiseo M, Filiberti R, Marroni P, Grossi F, Paganuzzi M: Decline in serum carcinoembryonic antigen and cytokeratin 19 fragment during chemotherapy predicts objective response and survival in patients with advanced nonsmall cell lung cancer. Cancer 2006, 107:2842-2849.

3. Pujol JL, Grenier J, Daures JP, Daver A, Pujol H, Michel FB: Serum fragment of cytokeratin subunit 19 measured by CYFRA 21-1 immunoradiometric assay as a marker of lung cancer. Cancer Res 1993, 53:61-66.

4. Pierga JY, Deneux L, Bonneton C, Vincent-Salomon A, Nos C, Anract P, Magdelenat H, Pouillart P, Thiery JP: Prognostic value of cytokeratin 19 fragment (CYFRA 21-1) and cytokeratin-positive cells in bone marrow samples of breast cancer patients. Int J Biol Markers 2004, 19:23-31.

5. Gauthier H, Guilhaume MN, Bidard FC, Pierga JY, Girre V, Cottu PH, Laurence V, Livartowski A, Mignot L, Dieras V: Survival of breast cancer patients with meningeal carcinomatosis. Ann Oncol 2010, 21:2183-2187.

6. Harris L, Fritsche H, Mennel R, Norton L, Ravdin P, Taube S, Somerfield MR, Hayes DF, Bast RC Jr: American Society of Clinical Oncology 2007 update of recommendations for the use of tumor markers in breast cancer. $J$ Clin Oncol 2007, 25:5287-5312.

7. Cristofanilli M, Budd GT, Ellis MJ, Stopeck A, Matera J, Miller MC, Reuben JM, Doyle GV, Allard WJ, Terstappen LW, Hayes DF: Circulating tumor cells, disease progression, and survival in metastatic breast cancer. $N$ Engl J Med 2004, 351:781-791.

8. Cristofanilli M, Hayes DF, Budd GT, Ellis MJ, Stopeck A, Reuben JM, Doyle GV, Matera J, Allard WJ, Miller MC, Fritsche HA, Hortobagyi GN, Terstappen LW: Circulating tumor cells: a novel prognostic factor for newly diagnosed metastatic breast cancer. J Clin Oncol 2005, 23:1420-1430, Erratum in: J Clin Oncol. 2005, 23:4808.

9. Pierga JY, Hajage D, Bachelot T, Delaloge S, Brain E, Campone M, Dieras V, Rolland E, Mignot L, Mathiot C, Bidard FC: High independent prognostic and predictive value of circulating tumor cells compared with serum tumor markers in a large prospective trial in first-line chemotherapy for metastatic breast cancer patients. Ann Oncol 2011.

10. Eisenhauer EA, Therasse P, Bogaerts J, Schwartz LH, Sargent D, Ford R, Dancey J, Arbuck S, Gwyther S, Mooney M, Rubinstein L, Shankar L, Dodd L, Kaplan R, Lacombe D, Verweij J: New response evaluation criteria in solid tumours: revised RECIST guideline (version 1.1). Eur J Cancer 2009, 45:228-247.

11. Allard WJ, Matera J, Miller MC, Repollet M, Connelly MC, Rao C, Tibbe AG, Uhr JW, Terstappen LW: Tumor cells circulate in the peripheral blood of all major carcinomas but not in healthy subjects or patients with nonmalignant diseases. Clin Cancer Res 2004, 10:6897-6904.

12. The R Project for Statistical Computing. [http://www.R-project.org].

13. Hayes DF, Cristofanilli M, Budd GT, Ellis MJ, Stopeck A, Miller MC, Matera J, Allard WJ, Doyle GV, Terstappen LW: Circulating tumor cells at each follow-up time point during therapy of metastatic breast cancer patients predict progression-free and overall survival. Clin Cancer Res 2006 12:4218-4224.

14. Budd GT, Cristofanilli M, Ellis MJ, Stopeck A, Borden E, Miller MC, Matera J, Repollet M, Doyle GV, Terstappen LW, Hayes DF: Circulating tumor cells versus imaging-predicting overall survival in metastatic breast cancer. Clin Cancer Res 2006, 12:6403-6409.

15. De Giorgi U, Valero V, Rohren E, Dawood S, Ueno NT, Miller MC, Doyle GV Jackson S, Andreopoulou E, Handy BC, Reuben JM, Fritsche HA, Macapinlac HA, Hortobagyi GN, Cristofanilli M: Circulating tumor cells and [18F]fluorodeoxyglucose positron emission tomography/computed tomography for outcome prediction in metastatic breast cancer. J Clin Oncol 2009, 27:3303-3311.

16. Hayes DF, Zurawski VR Jr, Kufe DW: Comparison of circulating CA15-3 and carcinoembryonic antigen levels in patients with breast cancer. J Clin Oncol 1986, 4:1542-1550.

17. Molina R, Zanon G, Filella X, Moreno F, Jo J, Daniels M, Latre ML, Gimenez N, Pahisa J, Velasco M, et al: Use of serial carcinoembryonic antigen and CA 15.3 assays in detecting relapses in breast cancer patients. Breast Cancer Res Treat 1995, 36:41-48.

18. Vizcarra E, Lluch A, Cibrian R, Jarque F, Alberola V, Belloch V, GarciaConde J: Value of CA 15.3 in breast cancer and comparison with CEA and TPA: a study of specificity in disease-free follow-up patients and sensitivity in patients at diagnosis of the first metastasis. Breast Cancer Res Treat 1996, 37:209-216.

19. Yerushalmi R, Tyldesley S, Kennecke H, Speers C, Woods R, Knight B, Gelmon KA: Tumor markers in metastatic breast cancer subtypes: frequency of elevation and correlation with outcome. Ann Oncol 2012, 23:338-345.

20. Nakata B, Ogawa Y, Ishikawa T, Ikeda K, Kato Y, Nishino H, Hirakawa K. Serum CYFRA 21-1 is one of the most reliable tumor markers for breast carcinoma. Cancer 2000, 89:1285-1290.

21. Nakata B, Takashima T, Ogawa Y, Ishikawa T, Hirakawa K: Serum CYFRA 211 (cytokeratin-19 fragments) is a useful tumour marker for detecting disease relapse and assessing treatment efficacy in breast cancer. $\mathrm{Br} J$ Cancer 2004, 91:873-878.

doi:10.1186/bcr3114

Cite this article as: Bidard et al:: Assessment of circulating tumor cells and serum markers for progression-free survival prediction in metastatic breast cancer: a prospective observational study. Breast Cancer Research 2012 14:R29. 